\title{
Os bebês com síndrome de Down e seus pais: novas propostas para intervenção
}

\author{
Babies with Down syndrome and their parents: \\ new proposals for intervention
}

\author{
Fernanda TRAVASSOS-RODRIGUEZ \\ Terezinha FÉRES-CARNEIRO
}

\begin{abstract}
Resumo
Esta investigação teve por objetivo estudar as concepções de pais e de profissionais sobre a comunicação do diagnóstico da síndrome de Down nas maternidades, bem como avaliar o dispositivo de estimulação precoce. Foram entrevistados seis mães e um pai, e oito profissionais. Das cinco categorias que emergiram da análise do conteúdo das entrevistas, duas foram destacadas neste trabalho: o momento da notícia e a estimulação precoce. Verificou-se que os pais sentem-se pouco acolhidos nas maternidades e pouco incluídos nos procedimentos de estimulação dos filhos. Constatou-se ainda que os profissionais dos centros obstétricos, que comunicam aos pais o diagnóstico do filho, e os terapeutas que realizam a estimulação precoce do bebê, em geral, não consideram os aspectos relacionais entre os membros do conjunto pais-bebê-profissionais como parte do próprio trabalho. Este trabalho apresenta uma proposta inovadora, com formas alternativas de atendimento que incluam os aspectos vinculares nesses dispositivos clínicos.
\end{abstract}

Unitermos: Intervenção precoce. Relação pais-criança. Síndrome de Down.

\begin{abstract}
The goal of this investigation was to study the concepts of both parents and professionals regarding the communication of Down syndrome diagnosis in maternities, and to evaluate the early stimulation device. Six mothers, one father, and eight professionals were interviewed. From the five categories emerged in the content analysis of interviews, we emphasize two of them to present in this work: the communication moment and early stimulation. We noticed that parents feel poorly assisted in maternities, as well as poorly included in early stimulation procedures with their babies. In addition, we found out that professionals in birth centers - who communicate the diagnosis to parents - and therapists who conduct the baby's early stimulation do not generally consider the relational aspects among the members of the group parents-baby-professionals as part of their work. We present an innovative proposal of alternative forms of assistance that include the bonding aspects in clinical devices.
\end{abstract}

Uniterms: Early intervention. Parent child relation. Down syndrome.

O nascimento do bebê com Síndrome de Down

(SD) sem diagnóstico pré-natal configura, na maioria das vezes, um momento traumático para familiares e até mesmo para os profissionais envolvidos no parto.

\section{$\cos$}

1 Pontifícia Universidade Católica do Rio de Janeiro, Centro de Teologia e Ciências Humanas, Departamento de Psicologia. R. Marques de São Vicente, 225, Gávea, 22453-900, Rio de Janeiro, RJ, Brasil. Correspondência para/Correspondence to: T. FÉRES-CARNEIRO. E-mail: <teferca@puc-rio.br>. 
Sem um protocolo de intervenção específico para tais casos, e muitas vezes angustiados pelas questões que tal tipo de acontecimento pode suscitar, os profissionais encaminham o bebê para uma série de especialistas. Vários exames são feitos, pois a criança com SD pode apresentar uma série de problemas clínicos. E, na ausência de uma cardiopatia grave, o bebê é encaminhado desde a mais tenra infância, no máximo aos três meses de idade, para a estimulação precoce.

Desde o momento da constatação da síndrome, o cerne de todo o trabalho se dá sobre a"problemática" do bebê, visto que todo o cuidado profissional se volta para a criança recém-nascida. Enquanto isso, os pais, que passam por um momento dramático e muito delicado, permanecem sem a devida assistência, visto que não se leva em conta que a notícia desse diagnóstico Ihes golpeia o próprio narcisismo, principalmente quando vivenciam com esse filho a primeira experiência parental. Com frequência, a assistência aos pais, ou aos familiares de maneira mais ampla, não é considerada relevante nos centros obstétricos, nem nos centros de estimulação precoce. Em contraste, no que diz respeito ao bebê, tudo é feito em velocidade máxima, dada a urgência concreta de tratar os problemas clínicos e desenvolvimentais que ele pode apresentar.

Busca-se, neste estudo, investigar a peculiaridade da formação dos vínculos na relação pais-bebê com SD e no conjunto família-profissionais-bebê, demarcando as possíveis implicações desse "encontro" para o desenvolvimento e a construção subjetiva da criança, e também para a assunção dos papéis parentais, atravessados muito precocemente pelo contexto da instituição de saúde.

Investiga-se ainda a relevância do profissional da área de psicologia nas maternidades e nos programas de estimulação precoce, atuando nas interfaces família-profissionais-bebê, já que os aspectos emocionais de todos eles estão envolvidos e vão repercutir tanto no desenvolvimento da criança quanto na fundação de uma estrutura familiar mais saudável no que diz respeito ao domínio psicológico.

\section{As primeiras relações pais-bebê com síndrome de Down e assistência perinatal}

Winnicott (1993) coloca que um bebê não existe, 832 e que ele só pode existir relacionado à maternagem.
Sabe-se que a sobrevivência nos seres humanos não se garante sem ajuda de um adulto que desempenhe determinadas funções. Um recém-nascido, mesmo quando se encontra em seu melhor estado, apresentando todas as competências mencionadas por Brazelton (1980), não tem nenhuma possibilidade de sobreviver sem a ajuda do seu semelhante. É a partir desse desamparo inicial, dessa dependência absoluta de um outro que desempenhe a função de maternagem, que na espécie humana são forjados o psiquismo e a capacidade de pensar (Bion, 1994).

No nascimento do bebê com SD, sem um diagnóstico pré-natal, observa-se uma situação particular. Os primeiros encontros entre os pais e o bebê, fundamentais para o engajamento emocional e para a experiência de vinculação, precursores do psiquismo e da capacidade de pensar, são fortemente perturbados pela notícia da síndrome. Além disso, muitas vezes, os profissionais que lidam com a situação ficam tão perplexos com o fato que, ao invés de contribuir para dar continência às angústias dos pais, também se angustiam, tumultuando mais ainda esse momento inicial. Os pais acabam tendo subtraída a experiência de intimidade com o bebê que, com frequência, antes de ser apresentado à família já recebeu um diagnóstico clínico. Assim, uma mãe entrevistada neste estudo relatou que "a sindrome de Down chegou antes da minha filha".

M. H. Klaus e P. H. Klaus (2001) ressaltam que muitos pais querem que esses momentos logo após o nascimento do filho sejam sagrados - só deles e do bebê. Essa é uma experiência significativa e emocionante, da qual eles se lembrarão para sempre. Parece, portanto, que geralmente os pais de bebês com SD carecem de uma experiência de parentalidade mais íntima, visto que são privados do momento em que se inicia o conhecimento do bebê real. Muitas vezes, são "atropelados" por uma equipe de saúde que comunica apenas um dos familiares - pai ou mãe -, sobre a suspeita da SD, sem ao menos trazer o bebê para que ele possa ser visto.

Para Rossel (2004a), antes de comunicar o diagnóstico da SD aos pais, seria conveniente oferecer a eles a oportunidade de estar com o bebê logo após o parto, ou logo que seja possível. Esta conduta, segundo Rossel (2004a), favoreceria o apego e os vínculos entre pais e filho. 
Buzatto e Beresin (2008) afirmam que a qualidade de vida dos pais de crianças com SD é afetada principalmente no domínio psicológico. Os autores apontam que o nascimento de um bebê com SD pode resultar em grande abalo psíquico para os pais, gerando uma confusão de sentimentos que permanece presente através do tempo.

Sunelaitis, Arruda e Marcom (2007) consideram que a comunicação do diagnóstico de SD exerce um grande impacto sobre a família. Em estudo de campo, as autoras depararam-se com a frequente situação da mãe do bebê receber a notícia do diagnóstico sozinha na maternidade.

Rossel (2004a; 2004b) considera que o diagnóstico da SD pode desencadear uma dificuldade de apego e vinculação entre pais e filho. Um afastamento inicial entre eles pode, para a autora, provocar um efeito em cascata de eventos emocionais negativos. Nesses casos, a possibilidade de fracasso do mecanismo de apego e do processo de vinculação é iminente, e o risco para o desenvolvimento do bebê é incalculável.

Os pais, na maioria das vezes, nocauteados pelo golpe da notícia da síndrome, ficam tristes e pouco receptivos ao bebê, que tem menos condições de envolvê-los, o que cria um desencontro. Dommergues, Bader-Meunier e Epelbaum (2003) mencionam que alguns pais chamam a atenção exatamente pela falta de expressão do afeto, lidando com a constatação do diagnóstico do filho de maneira muito técnica e racionalizada. Para Pereira-Silva e Dessen (2003), a inconsistência, encontrada nos relatos verbais acerca dos sentimentos em relação ao filho com SD, denota a dificuldade dos pais em aceitar a síndrome.

Rossel (2004b) observa que os pais que permanecem paralisados, negando deficiência da criança, ocultam sentimentos de tristeza e dor. Nesses casos, ficam inalcançáveis sob um manto de serenidade e compreensão exacerbada. Para Sousa, Ribeiro e Melo (2009), repetidas vezes os pais tentam ignorar o diagnóstico da SD para amenizar o sofrimento que estão vivenciando, e, com isso, acabam negando a realidade. Quando é assim, as relações familiares como um todo estão em risco, principalmente para aqueles que estão inaugurando o exercício da parentalidade.

Questiona-se aqui se as rupturas que levam a um desencontro, nesta dança que envolve o bebê e seus pais em um período tão crítico, poderiam tornar ainda mais difícil, para o bebê com SD, a emergência das funções psíquicas e cognitivas que sustentam e possibilitam seus processos de pensamento. Para Winnicott (1986), uma mudança na competência e na disponibilidade dos pais em criar um "espaço potencial" perturba a constituição da autonomia do filho.

O momento da notícia da síndrome de Down logo após o parto foi considerado o momento mais difícil para as famílias nas pesquisas de Bolsanello (1998), Casarin (1999) e de Pereira-Silva e Dessen (2006). A comunicação do diagnóstico, na maioria dos casos, é feita pelo próprio médico que realizou o parto, e a maneira pela qual é transmitida aos pais causa muita insatisfação (Bolsanello, 1998; Pereira-Silva e Dessen, 2003; Sousa et al., 2009). Para Dommergues et al. (2003), a comunicação do diagnóstico de uma deficiência aos pais, por mais cautelosa e empática que seja, será sempre uma provação para eles, de modo que os médicos deveriam torná-la menos destrutiva e dolorosa para os pais.

Bolsanello (1998; 2003) menciona a importância do trabalho com as mães de bebês com algum tipo de deficiência. Em sua pesquisa, observou reações intensas de dor, angústia, medo, confusão mental e sensação geral de incompetência que se desdobram em uma grande dificuldade em exercer a função materna. Bolsanello $(1998 ; 2003)$ ainda acrescenta que a maioria das parturientes estudadas considerava a condição do bebê como um "castigo de Deus". Ela interpreta essa expressão como uma possível explicação para os intensos sentimentos de culpa que as mães demonstram em relação à hostilidade dirigida ao próprio bebê. O sentimento de culpa também é mencionado por Casarin (1999), que ressalta que a necessidade de prover em excesso a criança pode estar relacionada à culpa vivenciada pelos pais.

No estudo de Pereira-Silva e Dessen (2003), a reação inicial das mães era de preocupação. Elas fomentavam uma imagem muito negativa a respeito da criança. Na pesquisa de Sousa et al. (2009), o momento pós-diagnóstico foi considerado pelos pais como um processo de luto. O sentimento referido com mais frequência foi o medo. Outros sentimentos mencionados pelos entrevistados foram culpa, impotência, raiva, tristeza, desespero, vergonha e rejeição. 
Segundo Rossel (2004a), após a comunicação de um diagnóstico como o de SD, a equipe de saúde deveria estar afinada para facilitar e reforçar o apego e a vinculação entre o bebê e os pais. Para tanto, deveria encorajar a amamentação ao seio e o contato direto com a mãe e o pai. Este procedimento, na experiência de Rossel (2004a), reduziria os sentimentos de ambivalência e negação posteriores.

Sunelaitis et al. (2007) também ressaltam que a ajuda e a mediação profissional frente ao diagnóstico de SD podem atenuar o impacto quando é possível sublinhar o potencial do bebê, e não apenas os aspectos negativos. Na mesma linha, Dommergues et al. (2003) enfatizam que devem ser favorecidas todas as palavras que deixem uma referência positiva em relação ao bebê. Esta conduta, segundo Dommergues et al. (2003) e Sunelaitis et al. (2007), pode contribuir no investimento dos pais sobre o filho. Para Sousa et al. (2009), com frequência os sentimentos negativos frente ao diagnóstico da SD podem ser amenizados quando os pais foram atendidos em suas angústias por profissionais habilitados para dar apoio nesse contexto. Isso, na visão das autoras, refletiria na relação entre pais e filhos, facilitando a resolução do luto inicial e, consequentemente, o desenvolvimento da criança.

Buzatto e Beresin (2008) mencionam que há uma sobrecarga psicológica nos pais, referente ao cuidado com a criança. Ansiedade, incerteza e insegurança são sentimentos que atravessam a parentalidade com um bebê que requer cuidados especiais. Nesse sentido, Pereira-Silva e Dessen (2006) evidenciam que mães de crianças com SD têm índices mais elevados de stress do que mães de crianças com desenvolvimento típico. As autoras sublinham que o stress parental influi na interação com a criança e, consequentemente, sobre seu desenvolvimento.

Em função do atendimento usualmente conturbado nas maternidades, Sunelaitis et al. (2007) afirmam que a comunicação do diagnóstico de SD deveria ser planejada, visando à importância do apoio da rede familiar e dos próprios profissionais de saúde. Rossel (2004b) estabelece a necessidade de as equipes de saúde das maternidades consolidarem um plano de trabalho para dar suporte emocional às famílias que têm filhos com SD. Para ela, sustentar os pais é erguer o alicerce fundamental em prol da defesa e proteção da criança.

\section{Uma trajetória especial: da comunicação do diagnóstico da SD ao dispositivo de estimulação precoce}

Faria (2000) menciona que os sinais físicos apresentados pelo bebê com SD podem ser estigmatizadores, mas que eles também permitem uma identificação imediata pela equipe da sala de parto. Para Faria (2000), as equipes frequentemente se desorganizam, tanto em nível afetivo quanto no pensamento clínico, por se sentirem feridas narcisicamente pelo nascimento de um indivíduo que as coloca frente à sua impotência e a seu limite como profissionais.

Para Acquarone (2004), lidar com a dor, com a deficiência e com a morte faz com que o profissional de saúde invista um quantum maior de energia que o usual na contínua reativação dos sentimentos relacionados a essas questões, para se proteger da tristeza, da impotência e do desconforto. Dessa forma, na visão das autoras deste estudo, nas maternidades e nos centros de estimulação precoce, a prioridade - que deveria ser a facilitação da relação pais-bebê com SD -, passa a ser o atendimento da demanda da própria equipe, em seu encontro com suas angústias pessoais.

Por todos esses aspectos que perturbam a vinculação inicial entre pais e filhos, este estudo considera que a criança com SD, além da deficiência, tem fatores de risco ambientais em relação a seu desenvolvimento. Nunes (1998) pondera que os serviços de estimulação precoce são direcionados para proporcionar, à criança de risco e à deficiente até três anos, as experiências necessárias que garantam, a partir de seu nascimento, o desenvolvimento máximo de seu potencial.

Os programas de estimulação precoce iniciaram-se nos Estados Unidos na década de 60, e no Brasil em 1973. Paulatinamente foram internacionalmente deslocando seu foco do modelo centrado na criança para um modelo que inclui a família e a comunidade (Almeida, 2004). No Brasil, segundo Bolsanello (1998; 2003), esse tipo de atendimento ainda é baseado, na maioria das instituições, no modelo centrado na criança; e, ainda, o tipo de atuação limita-se à função deficitária da criança, sem vê-la em sua totalidade. A autora conclui que, para os profissionais entrevistados, o objetivo da estimulação precoce era apenas sanar ou atenuar os deficits da criança e promover seu desenvolvimento. 
Assim, a interação entre pais e filhos não era considerada relevante nesse contexto. Nesse ponto, Brazelton (1980) salienta que os terapeutas, na ânsia de promover o desenvolvimento do bebê, ignoram sua relação com os pais e, em consequência, obtêm resultados aquém dos que poderiam ser atingidos em um trabalho que incluísse tais interações.

Bolsanello (1998; 2003) ainda constatou que os profissionais envolvidos no trabalho de estimulação precoce sentem-se despreparados tanto para lidar com a criança quanto com a família. Os terapeutas que a pesquisadora entrevistou não conseguiram relacionar nenhuma abordagem teórica que fundamentasse o trabalho desenvolvido com as crianças com SD, apesar de grande parte ter pós-graduação na área de Educação Especial. De forma paradoxal ao tipo de atendimento prioritariamente mecanicista, os mesmos entrevistados, em sua maioria, acreditavam que o fundamental para o bom atendimento em estimulação precoce era um vínculo afetivo entre os profissionais e a criança, além de disponibilidade para o trabalho.

Jerusalinsky e Coriat (1983) consideram que esse tecnicismo na estimulação precoce é uma verdadeira tautologia, já que o sistema nervoso do ser humano tem tanta plasticidade que seria impossível não obter nenhum resultado no comportamento introduzindo algum tipo de estimulação. Segundo Jerusalinsky e Coriat (1983), medir e estimular áreas específicas do desenvolvimento de maneira dissociada não ajuda a introduzir o sujeito (bebê) na comunicação e na linguagem, processos que fundamentam o ser humano como tal.

Na estimulação precoce, o atendimento ao bebê focaliza as áreas motoras, em detrimento dos aspectos psicológicos. Este estudo considera que tal conduta constitui uma lacuna importante nessa clínica, já que a estimulação precoce se dá durante a constituição do psiquismo do bebê e a formação dos primeiros esquemas cognitivos. Sabe-se da importância dos aspectos relacionais e, sobretudo, do exercício da função materna para o desenvolvimento do bebê, vínculo esse que muitas vezes é rompido no nascimento da criança com SD, mas que pode ser recuperado a partir do investimento terapêutico no processo de estimulação precoce que inclui os aspectos vinculares entre pais e filhos.
Assim, este estudo propõe uma clínica de estimulação que contribua para o resgate da competência parental, co-construindo novas expectativas em relação ao bebê e apostando na emergência do desejo dos pais em investir no próprio filho, visto que a deficiência mental presente na SD não impede que a criança desenvolva seu psiquismo de forma saudável.

Rossel (2004b) ressalta que o desempenho da criança com SD na estimulação precoce é frustrante quando existem falhas importantes na origem dos processos de vinculação entre ela e os pais. Segundo Rossel (2004b), nada dificulta mais as relações entre os pais e os filhos com SD que o isolamento social e a falta de integração, que não são mais do que uma falência na vinculação inicial pais/bebê.

Stray-Gundersen (2007) também menciona a importância dos programas de estimulação precoce centralizados na família. Eles devem levar em conta as particularidades não só da criança, mas também as da família. Nesse sentido, Pereiro (2000) ressalta que o conceito de estimulação precoce vem evoluindo na direção de incluir, além da criança, a família e a comunidade.

Este estudo desenvolveu uma pesquisa qualitativa, de acordo com as propostas de Bardin (2003) e Turato (2003), com o intuito de melhor compreender o universo das famílias que têm bebês com SD e dos profissionais da área. Foram investigadas as concepções de pais e de profissionais sobre o momento do diagnóstico da SD, bem como o dispositivo de estimulação precoce.

\section{Método}

\section{Participantes}

Os sujeitos entrevistados são seis mães e um pai cujos primeiros filhos nasceram com SD sem diagnóstico pré-natal, e oito profissionais, sendo dois obstetras, dois geneticistas, dois psicólogos, um fisioterapeuta e um fonoaudiólogo.

\section{Procedimentos}

As mães foram nomeadas como M (M1 a M6) e o pai como P1; e os profissionais como PO1 e PO2 (obste- 
tras), PG1 e PG2 (geneticistas), PP1 e PP2 (psicólogos), PFi1 (fisioterapeuta) e PFo1 (fonoaudiólogo).

Para a coleta dos dados foram utilizadas entrevistas semiestruturadas com roteiro invisível, realizadas separadamente com cada membro da família ou profissional. Os encontros foram gravados em áudio e transcritos na íntegra. O estudo foi aprovado pela Comissão de Ética do Departamento de Psicologia da Pontifícia Universidade Católica do Rio de Janeiro, tendo sido solicitado aos participantes que lessem e assinassem o Termo de Consentimento Livre e Esclarecido.

\section{Resultados e Discussão}

A partir da avaliação do conteúdo das entrevistas, emergiram cinco categorias de análise: o momento da notícia, a estimulação precoce, a síndrome de Down, o luto e a formação dos laços afetivos. Para este estudo, foram destacadas as duas primeiras categorias.

\section{Momento da notícia}

O momento da notícia, como é chamada por pais e profissionais a ocasião da comunicação do diagnóstico da síndrome de Down, foi considerado pelos pais o período mais difícil dessa trajetória.

"... mais difícil? É a notícia. ... eu tô esperando aquela criança perfeita e vem esse choque: seu filho tem síndrome de Down. É um choque muito grande" (M4).

"Ah! Eu diria a notícia. Acho que foi o pior momento da minha vida, foi aquela hora ali no corredor" (P1).

Os achados corroboram as pesquisas de Bolsanello (1998), Casarin (1999) e Pereira-Silva e Dessen (2003), nas quais os pais também consideraram o pior momento da história com o filho a comunicação do diagnóstico da SD. Os sentimentos que surgem nos pais, durante e logo após o momento da notícia, são intensos e sua importância dentro da relação com o bebê deve ser considerada. O sentimento relatado como o choque com a notícia do diagnóstico da SD após o nascimento do bebê surgiu espontaneamente na fala de todos os participantes da pesquisa. Esse sentimento também foi mencionado na pesquisa de Pereira-Silva e Dessen (2003). A notícia era completamente inesperada, visto que to836 das as gestantes fizeram acompanhamento pré-natal e nenhuma suspeita da SD, nem de nenhum outro tipo de alteração, foi mencionada durante o período da gravidez.

"... o choque que a gentelevaé um choque muito grande. ... o mundo desabou para mim, já comecei a chorar, foi aquele choque"(M4).

"Naquele momento ali, fiqueichocada... lógico que o meu mundo ruiu..." (M5).

Saber que o filho tem SD interrompe o narcisismo nascente dos pais de forma abrupta, causando-Ihes perplexidade frente à notícia para a qual não houve nenhum tipo de preparo.

A ambivalência em relação ao filho surge no discurso de alguns entrevistados:

"... eu quero, mas eu não quero com Síndrome de Down" (M4).

"É porque às vezes ele (o marido) não me permitia ter as minhas crises de dúvidas queénormal. Umavez... eu tive uma crise,... eu olhei aquele bando de criança, eu falei:Putz! Por que o meu é o diferente daquele bando de criança?" (M5).

Se a ambivalência está presente na relação pais-bebê com ou sem SD, no nascimento da criança sem a síndrome ela é apaziguada pelas projeções narcísicas dos pais em relação ao bebê. No caso de um bebê com SD, a polaridade de sentimentos é mais presente e intensa, visto que o bebê ideal se desmaterializa instantaneamente.

A ambivalência também é mencionada no estudo de Rossel (2004b) como um dos sentimentos mais comuns, nos pais de bebê com SD, após o diagnóstico. Já a negação, também observada no discurso dos entrevistados nesta pesquisa, é mencionada por Dommergues et al. (2003), Pereira-Silva e Dessen (2003), Rossel (2004b) e Sousa et al. (2009). O mecanismo de negação surge como uma defesa e uma tentativa de manter a representação do bebê idealizado na mente dos pais.

"Eu achava que aquilo não era verdade, de que... Podia ser revertido" (M4).

"o dia que chegou o resultado (do cariótipo) foi um marco. Parei de ficar achando que a coisa não era, que não é, entendeu? Eu tinha uma esperança" (M5).

A ambivalência e a negação que surgem nos discurso dos entrevistados relacionam-se também ao 
tema da culpa que, atrelado a um conteúdo de cunho religioso, introduz um significado de recompensa ou punição divina, o que faz com que os pais vejam o filho ora como um "presente", ora como um "castigo de Deus".

"A minha irmã começou a gritar, chorar desesperadamente, a minha mãe: 'Lúcia, calma, Deus sabe o quefaz, tá? Se ele deu pra sua irmã, é porque Ele sabe que ela é capazde cuidar. Sabe que ela é merecedora disso', né?" (M3).

"Assim, eu fiqueipensando, tipo, o que que a gente fez pra merecer aquilo. Por que cargas d'água? O que eu tinha feito para o mundo para receber aquele castigo, entre aspas, né? De ter um filho com Síndrome de Down"(M5).

Esses resultados estão de acordo com aqueles obtidos por Bolsanello (1998), que mostram que a maioria das parturientes estudadas considerava a deficiência do bebê como um "castigo de Deus".

Outros sentimentos como a tristeza e o desespero foram ressaltados pelos pais entrevistados como consequência do momento da notícia. A tristeza encontrada nesta pesquisa corrobora a pesquisa de Pereira-Silva e Dessen (2003), e o desespero, que foi um dos principais sentimentos mencionados pelos pais, também está de acordo com os achados de Sousa et al. (2009).

"Na minha mente, a hora que eu vi os quatro membros dele sumiu da minha cabeça, pra mim ele não tinha uma perna, não tinha um braço, fiquei desesperada ... eu falei, bom, deve estar ruim, deve ter morrido até" (M2).

"... eu fiquei desesperada, fiquei desesperada não aceitava ecomeceichorar, chorar, chorar. Aínada mefazia para dechorar"(M4).

Esses sentimentos estão presentes e se intercalam à medida que vai sendo possível a elaboração do luto pelo bebê sonhado e torna-se possível a adaptação e vinculação dos pais ao bebê real.

Percebe-se, assim como Rossel (2004a), que a proximidade e o contato com o bebê, principalmente antes da notícia relativa à SD, facilitam a emergência do apego e a vinculação entre pais e filho. A ideia baseia-se na premissa de que esses processos poderiam emergir com fluidez se os pais pudessem vê-lo e senti-lo como ele realmente é, sem que nenhum rótulo ou estigma se interponha na relação.

"Eu acho que assim, essa coisa de ter tido contato antes (de ter o diagnóstico da SD) com o bebê foi fundamental.
Eu não sabia de nada, meu filho veio pro meu colo, não percebi absolutamente nada. Achei ele lindo, maravilhoso, ele pegou no meu peito de imediato. Assim, não tive problema nenhum pra amamentar" (M5).

A maioria dos pais entrevistados recebeu a notícia da SD sozinhos e ainda a incumbência de transmiti-la ao outro cônjuge. A situação suscitou-lhes uma grande sobrecarga emocional e provocou uma indignação em relação aos profissionais que os assistiam.

"Acho que deveria ter sido falado sim, mas de uma outra
forma, na presença do meu marido" (M1).
"Então eu acho que poderia ter sido muito mais fácil,...
menos doloroso pra mim se ela viesse contar para a gente
junto e não esconder de mim" (M2).

Esses dados confirmam as pesquisas de Dessen e Pereira-Silva (2003) e de Sunelaitis et al. (2007), nas quais foram destacados relatos frequentes das mães recebendo sozinhas o diagnóstico dos filhos. A insatisfação com o momento da notícia também é enfatizada nos estudos de Bolsanello (1998) e Sousa et al. (2009).

Na fala dos profissionais, tal fato se dá, muitas vezes, por questões práticas e institucionais. Sendo assim, tais condutas não parecem ser questionadas.

"Normalmente, assim, este tipo de notícia, a gente acaba falando só com a mãe porque as pacientes ficam em apartamentos sem acompanhantes. A gente, normalmente, como obstetra, vai ter um último contato, na hora da alta, só com a mãe, sem o resto da família, então, a notícia é dada para a mãe" (PO1).

Portanto, é ainda na maternidade que se iniciam os variados embates com a equipe de atendimento que, na urgência e angústia de comunicar a deficiência da criança para os familiares, usam um vocabulário muito técnico, que os deixa mais confusos, sem saber o que fazer com tanta informação. No discurso de um dos profissionais:

"Eles (os pais) ouvem aqueles termos (médicos), meio perdidos, mas ninguém perdeu tempo, literalmente em sentar e conversar com aquela família" (PG1)

A fala dos pais entrevistados acerca do atendimento profissional nas maternidades varia, mas para a maioria das famílias essa relação não foi muito fácil, apontando o despreparo e falta de informação mais atualizada sobre a SD por parte das equipes.

"Me disseram para não esperarmuito dele.... Acheide uma falta de tato e informação" (M1). 
"Bom, eu achei que a médica foi um pouco... a... talvez, arrogante, eu não sei se essa é a palavra certa de se falar ... ela falou de sopetão..."(P1).

Este tipo de avaliação também aparece nas pesquisas de Bolsanello (1998), Pereira-Silva e Dessen (2003) e Sousa et al. (2009), nas quais os entrevistados apontam o despreparo da equipe médica. No entanto, para Dommergues et al. (2003), por mais que os profissionais sejam empáticos e cuidadosos, a notícia será sempre dolorosa para os pais. Nesse sentido, recomendam que talvez fosse papel dos profissionais tentar tornar o momento da comunicação do diagnóstico menos destrutivo para os familiares, devendo ressaltar também os aspectos positivos e as potencialidades do bebê, por exemplo.

O conteúdo da informação também parece ter muita relevância. Nesse sentido, alguns profissionais entrevistados concluem que "os anos de experiência mudaram as suas condutas".

"... eu tento sempre puxar a notícia pela própria família, e não chegar e dizer tem (aSD), e começar a soltar aquele monte de informações em relação ao diagnóstico, até porque naquele momento eles não são capazes de absorvernadadisso" (PG2).

Neste sentido, Dommergues et al. (2003), Rossel (2004a, 2004b), Sunelaitis et al. (2007) e Sousa et al. (2009) consideram que a equipe de saúde perinatal deveria antecipadamente elaborar estratégias que facilitem e reforcem, no momento do diagnóstico, o apego e a vinculação entre os pais e o bebê, principalmente logo após o parto.

\section{Estimulação precoce}

As definições conceituais do termo estimulação precoce, nomeadas pelos profissionais entrevistados, são confusas e incoerentes com sua prática clínica. Os aspectos emocionais do bebê, assim como o entrelaçamento psíquico dos pais com o filho, não são considerados como parte do trabalho a ser desenvolvido. A visão predominante dos profissionais ainda é mecanicista e centrada na deficiência da criança, dividindo-a em "partes" passíveis de intervenção especializada, o que não ajuda em sua integração.

“...é uma estimulação como prevenção, por exemplo, eu como fono, tô pensando na fala, tô pensando na alimentação quejá está iniciando" (PFo1).
"Éum investimento na criança. Luto para ela desenvolver a marcha" (PFi1).

Os achados deste estudo corroboram os de Jerusalinsky e Coriat (1983), Jerusalinsky (2001) e Bolsanello $(1998,2003)$, que também consideram que o especialismo e tecnicismo das estimulações dividem a criança em partes e não a veem com um ser integrado. Nesse sentido, a estimulação precoce deixaria de cumprir a importante função de promover a interação e vinculação entre pais e filhos.

Na presente pesquisa, a principal função da estimulação precoce, para os pais, diferentemente dos profissionais, é dar suporte e promover a integração familiar, enfatizando a importância da interação com o filho. A partilha de responsabilidade entre a família e a equipe de trabalho exerce uma importante função de acolhimento para os pais.

"O que seria de mim se não fosse a estimulação? Para mim semprefoi meu porto seguro, tá? Como lidar, como cuidar... Claro. A minha primeira equipe foi maravilhosa! Nunca vou esquecer porque tem um carinho muito grande" (M3).

Apesar desse tipo de relato predominar na fala dos pais entrevistados, a visão teórica dos profissionais parece distante dessa perspectiva. Em alguns métodos de estimulação precoce ainda são prescritas muitas condutas terapêuticas para os pais, o que Ihes pode tolher a espontaneidade no trato com o filho, não colaborando para o resgate da competência parental e da função materna (Jerusalinsky \& Coriat, 1983; Jerusalinsky, 2001).

"Você ia lá seis vezes por mês, ela analisava a criança, passava exercícios, via você fazendo os exercícios para ver se estavam sendo corretos, te mandava pra casa. Passavaum mês, vocêvoltava efazia tudo de novo" (P1).

As condutas prescritivas e tecnicistas são questionadas por poucos profissionais:

"... isso é uma exigência muito "hard" em cima da família ... estimulações que exigem treinamentos dos pais, eu acho isso uma maldade ... Deposita-se toda a responsabilidade na mão da família, se não der certo, a culpaé dafamília" (PP1).

Percebe-se ainda, nos profissionais entrevistados, um grande impasse clínico que diz respeito à vivência intensa de sofrimento à qual são expostos. A falta de informação acerca dos aspectos vinculares, envolvidos na clínica com o bebê com SD e sua família, somada ao 
excesso de sobrecarga, que não costuma ser trabalhada nas instituições e clínicas privadas, impede que os terapeutas tenham um espaço psíquico para acolher a família com o bebê.

No entanto, alguns poucos entrevistados enfatizaram os aspectos dolorosos que envolvem essa clínica:

"Têm profissionais que são zero atingidos por isso. Mas... claro que atinge. Mas eu acho que o profissional tem que ser sensível o suficiente pra captar aquilo e para ver se tem alguma coisa a fazer. Não dá prasersótécnico, né?" (PG2).

Por outro lado, a maioria dos profissionais entrevistados negou que a problemática da família os atingisse emocionalmente de algum modo:

"Como assim atinge? Não atinge o profissional, não. Eu acho que o profissional tá muito longe de ter percepção do que isso acarreta sobre você.... Eu nunca vou chegar próximo do que é ter uma criança com Síndrome de Down"(PG1).

Nesse sentido, Acquarone (2004) ressalta que o profissional que trabalha com pessoas deficientes ou doentes tem que dispor de uma maneira para elaborar os sentimentos que esse tipo de temática suscita: tristeza, impotência e desconforto. Tais sentimentos, assim como alguns conflitos internos por eles reativados, ou deles derivados, deveriam ser discutidos em equipe, ao invés de ficarem camuflados ou negados, pois acabam por entravar a possibilidade de um "encontro" produtivo entre os profissionais, o bebê e a família.

\section{Considerações Finais}

Pensar um dispositivo que atenda à família do bebê que nasce com SD, a partir de uma perspectiva que englobe a psicologia do desenvolvimento e a psicologia clínica, subverte a ordem clínica na qual vêm sendo pensados e concebidos, de maneira geral, o atendimento nas maternidades e a estimulação precoce. A partir do entendimento propiciado por este estudo, entende-se que não se pode conceber uma clínica que proponha um trabalho com bebês, dissociado dos pais. Portanto, a formação dos profissionais envolvidos nesse contexto, de acordo com a proposta deste estudo, deveria ser reformulada a partir de uma ênfase no trabalho do psicólogo para lidar com as questões perti- nentes. Os profissionais precisam estar atentos às questões psíquicas dos pais e do bebê, respeitando sua singularidade e fornecendo-Ihes suporte para um exercício mais satisfatório das funções parentais.

Verifica-se o quanto o"encontro inesperado"dos pais com o primeiro filho, com SD, sem uma mediação cuidadosa por parte dos profissionais das instituições de saúde, pode trazer implicações profundas e duradouras na constituição subjetiva da criança, visto que perturba a formação dos vínculos entre pais e filhos. Tal fato pode alterar o curso do desenvolvimento da criança e subtrair dos pais a sensação de competência no exercício de suas funções junto ao bebê.

Nota-se, portanto, uma urgência no investimento do profissional que atua nessa área. Contudo, esta proposta de mudança exige uma transformação no tipo de intervenção vigente na clínica, algo que não se realiza em pouco tempo e depende de mudanças em nível institucional. Essas modificações seriam necessárias não só nas instituições que tratam dos bebês com SD, mas também nas instituições formadoras de profissionais que trabalham com tal clientela. Sem dúvida, seriam necessárias também reformulações nas políticas públicas de saúde mental.

Para finalizar, relembra-se aqui que o sujeito se constituiu na relação com o meio e, portanto, a subjetivação do bebê não depende apenas dos fatores constitucionais, mas também dos ambientais, os quais podem produzir efeitos benéficos ou patogênicos. 0 bebê com SD apresenta diversas questões constitucionais que entravam o curso de seu desenvolvimento e, por isso, sublinha-se a necessidade de um olhar profissional cuidadoso, que acolha precocemente a família, com a finalidade de que essas relações não sejam norteadas pela iatrogenia do diagnóstico da SD. Assim, considera-se que intervenções profissionais que não contemplem a importância da relação pais/bebê com SD dificultam o acionamento do potencial maturativo do bebê e seu advento como sujeito.

\section{Referências}

Acquarone, S. (2004). Special-needs babies: helping to secure attachment. In S. Acquarone. Infant-parent psychotherapy (pp.201-250). London: Karnac. 
Almeida, I. C. (2004). Intervenção precoce: focada na criança ou centrada na família e na comunidade? Análise Psicológica, 1 (22), 65-72.

Bardin, L. (2003). L'analyse de contenu. In S. Moscovici \& F. Buschini (Orgs.), Les méthodes des sciences humaines. Paris: PUF.

Bion, W. (1994). Uma teoria sobre o pensar. In Estudos psicanalíticos revisados (4a ed., pp.127-138). Rio de Janeiro: Imago. (Originalmente publicado em 1967)

Bolsanello, M. A. (1998). Interação mãe-filho portador de deficiência: concepções emodo de atuação dos profissionais em estimulação precoce. Tese de doutorado não-publicada, Universidade de São Paulo.

Bolsanello, M. A. (2003). Concepções sobre os procedimentos de intervenção e avaliação de profissionais em estimulação precoce. Educar em Revista, 22, 343-355.

Brazelton, T. B. (1980). O desenvolvimento do apego: uma família em formação. Porto Alegre: Artes Médicas.

Buzatto, L. L., \& Beresin, R. (2008). Qualidade de vida dos pais de crianças portadoras da síndrome de Down. Einstein, 6 (2), 175-181.

Carasin, S. (1999). Aspectos psicológicos da síndrome de Down. In S. Shwartzman (Org.), Síndrome de Down (pp.263-285). São Paulo: Menon.

Dessen, M. A., \& Pereira-Silva, N. L.(2003). Crianças com síndrome de Down e suas interações familiares. Psicologia: Reflexão e Crítica, 16 (3), 503-514.

Dommergues, J. P., Bader-Meunier, B., \& Epelbaum, C. (2003). A comunicação do diagnóstico da doença crônica na criança. In M. L. Gille. Boi da cara preta: crianças no hospital (pp.121-142). Salvador: Ágalma.

Faria, M. C. C. (2000). O estranho no ninho: o bebê com síndrome de Down. In C. M. F. Rohenkohl (Org.), A clínica com o bebê (pp.157-162). São Paulo: Casa do Psicólogo.

Jerusalinsky, J. (2001). Quando o que se antecipa é o fracasso... prevenção secundária e estimulação precoce. In M. C. Camarotti. Atendimento ao bebê: uma abordagem interdisciplinar (pp.35-42). São Paulo: Casa do psicólogo.

Jerusalinsky, A., \& Coriat, E. (1983). Função materna e estimulação precoce: experiência controlada com 100 sujeitos de 3 a 16 meses de idade cronológica. Escritos da Criança, 1, 76-85.
Klaus, M. H., \& Klaus, P. H. (2001). Seu surpreendente recém-nascido. Porto Alegre: Artmed.

Nunes, L. R. O. P. (1998). Educação precoce para bebês de risco. In Rangé, B. Psicoterapia comportamental e cognitiva (pp.121-141). São Paulo: Editora Psy.

Pereira-Silva, N. L., \& Dessen M. A. (2006). Padrões de interação genitores-crianças com e sem síndrome de Down. Psicologia: Reflexão e Crítica, 19 (2), 283-291.

Pereiro, M. H. V. M. (2000). Contributos para uma análise avaliativa da intervenção precoce: as representações dos profissionais. In F. R. Leitão. (Org.), A intervenção precoce e a criança com síndroma de Down (pp.177-198). Porto: Porto Editora.

Rossel, C. (2004a). Apego y vinculación en el síndrome de Down: uma emergencia afectiva. Revista Pediatría Electrónica, 1 (1), 3-8.

Rossel, C. (2004b). El recién nacido con síndrome de Down y el equipo de salud neonatal. Revista Pediatría Electrónica, 1 (1) 9-12

Sousa, J. I. G. S., Ribeiro, G. T. F., \& Melo, A. P. C. (2009). Síndrome de down: sentimentos vivenciados pelos pais frente ao diagnóstico. Pediatria, 31 (2), 100-108.

Stray-Gundersen, K. (2007). Crianças com síndrome de Down: guia para pais e educadores. Porto Alegre: Artmed.

Sunelaitis, R. C., Arruda, D. C., \& Marcom, S. S. (2007). A repercussão do diagnóstico de síndrome de Down no cotidiano familiar. Acta Paulista de Enfermagem, 20 (3), 264-271.

Turato, E. R. (2003). Tratado da metodologia clínico-qualitativa: construção teórico-epistemológica, discussão comparada e aplicação nas áreas da saúde e humanas. Petrópolis: vozes.

Winnicott, D. W. (1986). Holding and interpretation. London: Karnac.

Winnicott, D. W. (1993). Textos selecionados: da pediatria à psicanálise ( $4^{a}$ ed.). Rio de Janeiro: Francisco Alves. (Originalmente publicado em 1958).

Recebido em: 23/2/2011

Aprovado em: 16/2/2012 